\title{
3D Relief Cutting Process Using 2D Image Luminosity Grayscaling on The G-Weike WK1212 CNC Router Machine
}

\section{Proses Relief Cutting 3D menggunakan 2D Image Luminosity Grayscaling pada Mesin CNC Router G-Weike WK1212}

\author{
Dewa Kusuma Wijaya ${ }^{1}$, Pramudi Arsiwi ${ }^{1}$ \\ ${ }^{1}$ Fakultas Teknik \\ Program Studi Teknik Industri, Universitas Dian Nuswantoro \\ Jl. Nakula I no.5-11 Pendrikan Kidul, Semarang, 50131 \\ email :dewa.kuja@dsn.dinus.ac.id \\ doi: https://doi.org/10.31315/opsi.v14i2.5505
}

Received: $22^{\text {nd }}$ September 2021; Revised: $2^{\text {nd }}$ November 2021; Accepted: $3^{\text {rd }}$ November 2021;

Available online: $21^{\text {st }}$ December 2021; Published regularly: December 2021

\begin{abstract}
This study implements the image litophane processing method to convert $2 D$ images into $3 D$ designs using image luminosity grayscaling techniques, so that the design process as input data for CNC router machining operations can be carried out quickly to support rapid prototyping technology. Furthermore, this research will process the $3 D$ design into a $3 D$ engraving object with a relief cutting process using a $G$-Weike WK1212 CNC router machine. Using the image luminosity grascaling technique, the color composition value is obtained to change the grayscale color image by 33\% red, 59\% green and 11\% blue with a luminosity value of $35 \%$ or 89 from the range of luminosity grayscale levels 0 - 255. These results are further increased by $50 \%$ to 172 or $67 \%$ of the range of grayscale luminosity levels L[0, 255] so that it will be at the ideal luminosity value for the relief cutting process. Using a luminosity value of 172 from a grayscale image, the actual depth value is $1.82 \mathrm{~mm}$ from a total depth of $3 \mathrm{~mm}$, which of course the relief pattern will look good.
\end{abstract}

Keywords: image litophane processing, image luminosity grayscaling, rapid prototyping, CNC router, relief cutting

\begin{abstract}
ABSTRAK
Penelitian ini mengimplementasikan metode image litophane processing untuk merubah image $2 D$ menjadi desain 3D menggunakan teknik image luminosity grayscaling, sehingga proses pembuatan desain sebagai data input operasi permesinan CNC router dapat dilakukan secara cepat untuk mendukung teknologi rapid prototyping. Selanjutnya, penelitian ini akan memproses desain 3D tersebut menjadi objek ukiran $3 D$ dengan proses relief cutting menggunakan mesin CNC router G-Weike WK1212. Menggunakan teknik image luminosity grascaling diperoleh nilai komposisi warna untuk merubah image warna menjadi grayscale sebesar 33\% red, $59 \%$ green dan $11 \%$ blue dengan nilai luminosity sebesar 35\% atau 89 dari rentang tingkat luminosity grayscale 0 - 255. Hasil tersebut selanjutnya ditingkatkan sebesar 50\% menjadi 172 atau $67 \%$ dari rentang tingkat luminosity grayscale L[0, 255] sehingga akan berada pada nilai luminosity yang ideal untuk proses relief cutting. Menggunakan nilai luminosity sebesar 172 dari image grayscale maka diperoleh nilai depth aktual sebesar $1,82 \mathrm{~mm}$ dari total depth $3 \mathrm{~mm}$, yang tentu saja pola relief akan terlihat secara baik.
\end{abstract}

Kata Kunci: image litophane processing, image luminosity grayscaling, rapid prototyping, CNC router, relief cutting 


\section{PENDAHULUAN}

Proses relief cutting adalah proses pemotongan material untuk dibentuk menjadi pola relief 3 dimensi (3D) dengan bantuan permesinan berbasis Computer Numerical Control (CNC). Teknis proses tersebut adalah dengan cara mengikis secara bertahap dari material benda kerja untuk dibentuk lekukanlekukan (curved) pada setiap sisi profil yang dibuat sehingga hasil proses secara visual dapat menjadi 3D. Penelitian ini memanfaatkan mesin CNC router G-Weike WK1212 untuk proses permesinan relief cutting pada material kayu mahoni menggunakan mata pahat jenis end mill $3 \mathrm{~mm}$ dengan 2 mata pisau (flute) dan mata pahat jenis conical $3 \mathrm{~mm}$. Proses permesinan relief cutting ini akan memanfaatkan komposisi tingkat seting (level setting) yang telah optimal dari hasil penelitian sebelumnya, yang kemudian pada implementasinya akan digunakan untuk membuat objek 3D menggunakan gambar (image) 2D. Penelitian ini perlu dilakukan karena sejauh ini dalam memanfatkan mesin $\mathrm{CNC}$ router untuk memproses permesinan objek secara 3D masih dilakukan secara konvensional, yaitu memanfaatkan rancangan desain $3 \mathrm{D}$ yang sudah dibuat menggunakan bantuan software Computer Aid Design (CAD). Apabila revolusi industri 4.0 untuk permesinan $\mathrm{CNC}$ dikaitkan dengan proses pembuatan suatu produk atau prototipe secara cepat (rapid prototyping) maka hal ini perlu menjadi pertimbangan dikarenakan dalam pembuatan desain 3D membutuhkan waktu yang cukup lama. Beberapa alternatif solusi untuk membuat desain 3D secara cepat adalah pemanfaatan teknologi scanning 3D dan pemanfaatan proses pengolahan citra gambar menjadi desain 3D (image litophane processing) yang dikombinasikan dengan proses permesinan relief cutting.

Alternatif dalam capturing objek dalam pembuatan desain 3D secara cepat adalah menggunakan teknologi scanning 3D, dimana pada implementasinya perlu memanfaatkan alat scanner 3D yang tentu saja membutuhkan biaya yang cukup mahal dari alat scanner tersebut. Namun, pemanfaatan teknologi scanner 3D tersebut mampu menghasilkan desain 3D secara instan dan cukup akurat karena detil profil dapat ter-capture secara baik dengan asumsi 3D scan memiliki kemampuan pixel yang baik.
Pemanfaatan teknologi tersebut hanya dapat digunakan untuk objek fisik yang sudah jadi, kemudian dilakukan duplikasi dalam bentuk scan desain 3D dari objek tersebut dan apabila dikehendaki untuk dilakukan perubahan ataupun pengembangan dari desain 3D tersebut maka perlu diproses dengan bantuan software 3D CAD.

Penelitian ini memanfaatkan proses permesinan relief cutting untuk membuat objek 3D menggunakan mesin $\mathrm{CNC}$ router G-Weike WK1212. Adapun pada prosesnya, desain 3D akan diperoleh menggunakan image processing dari gambar 2D metode ini biasa dikenal dengan image lithopane. Metode image litophane processing 2D menjadi 3D ini mampu memproses desain 3D relatif cukup cepat dan tentu saja murah. Gambar 2D dapat diperoleh dari hasil rancangan desain menggunakan software CAD ataupun dapat diambil menggunakan kamera foto apabila sudah ada objek fisiknya. Pemanfaatan kamera foto tentu saja dapat mempersingkat waktu dalam memperoleh desain 2D, kemudian dari gambar tersebut dapat diproses menjadi 3D dengan teknologi image litophane processing dengan cara pemanfaatan bantuan software olah foto 3D ataupun secara manual menggunakan gradasi warna.

Penelitian ini menggunakan salah satu bentuk implementasi image lithopane processing yaitu teknik image luminosity grayscaling. Teknik tersebut akan merubah gambar berwarna 2D berwarna menjadi desain 3D dengan cara mentransformasi warna menjadi grayscale, selanjutnya diatur tingkat intensitas cahaya (uminosity) agar tingkat depth dari hasil proses permesinan $\mathrm{CNC}$ router nantinya dapat membentuk pola hasil ukiran yang baik. Proses relief cutting pada mesin $\mathrm{CNC}$ router tersebut sebelumnya akan menggunakan relief image yang merupakan bentuk desain 3D dari hasil pengolahan image luminosity grayscale. Relief image tersebut merubah image 2D menjadi 3D berdasarkan gradasi warna, warna yang dapat diproses adalah grayscale, sehingga dalam hal teknik proses image luminosity grayscale sangat sesuai untuk digunakan.

Proses relief cutting akan merubah image desain 3D dengan cara mengikis material secara bertahap dengan tingkat pemakanan tertentu berdasarkan tingkat luminosity dari image tersebut, dimana semakin rendah tingkat 
luminosity maka proses cutting akan semakin dalam dan begitu juga sebaliknya dengan rentang total nilai depth sesuai keinginan. Hasil dari penelitian ini diharapkan dapat memberikan acuan prosedur standar di dalam melakukan operasi permesinan mesin CNC router G-Weike WK1212 untuk proses relief cutting dalam memproses objek 3D secara cepat, tepat dan lowcost.

Penelitian terkait mesin CNC Router GWeike WK1212 untuk optimasi proses permesinan cutting telah dilakukan menggunakan faktor spindle speed, motion speed, dan depth per cut, dengan menggunakan parameter dimensi aktual dan waktu proses (Dewa et al., 2020). Kemudian dengan faktor dan parameter yang sama dilakukan penambahan parameter lanjut yaitu temperatur mata pahat dan tingkat cracking (Herwin \& Dewa, 2020).

Penelitian terkait mesin router untuk proses ukir atau carving atau juga disebut engraving juga telah dilakukan pada industri skala kecil menggunakan mesin $\mathrm{CNC}$ router 3 axis (Ginting et al., 2017). Pengembangan implementasi dilakukan menggunakan $\mathrm{CNC}$ router milling 4 axis di dalam membuat objek 3D berupa (PW \& I, 2016). Terkait objek 3D, penelitian untuk menkonversi desain 2D menjadi 3D dilakukan berdasarkan depth map generation (Yang et al., 2013)

Penelitian terkait pemanfaatan desain 3D untuk diproses menjadi objek ukiran telah diterapkan pada industri meubel menggunakan mesin CNC router (Darmawanto \& Minardi, 2017). Menggunakan material kayu, CNC router juga dipergunakan untuk memproses motif desain kain rumanian textile menjadi ukiran relief menggunakan teknik proses engraving dan $v$-carve (Lungu et al., 2021). CNC router selain dipergunakan untuk permesinan juga dilakukan simulasi pada proses pembuatan ukiran relief menggunakan material batu ukir ( $\mathrm{Wu}$ et al., 2012). Terkait simulasi proses permesinan CNC, menggunakan CAD-CAM proses embossing dilakukan simulasi terhadap material logam alumunium (Yu, 2017).

Pembuatan objek ukiran 3D dengan mesin $\mathrm{CNC}$ router 3 axis menggunakan foto yang dirubah menjadi 3D relief telah dilakukan terhadap beberapa jenis material kayu seperti kayu jati dan mahoni (Setyaningsih et al., 2021). Terkait proses permesinan 3D objek dengan mesin CNC menggunakan foto digital 2D berwarna yang diproses dengan image processing juga telah dilakukan penelitian (Sood et al., 2018). Penelitian ini akan membuat suatu produk relief 3D menggunakan relief image 3D yang diperoleh dari hasil transformasi foto digital berwarna 2D dengan teknik image luminosity grayscaling yang merupakan bagian dari image lithopane processing.

\section{METODE}

Penelitian ini dimulai dengan menetapkan rumusan masakah dan menentukan solusi yang sesuai. Solusi dari permasalahan yang ada berupa implementasi image processing dengan teknik image luminosity grayscale yang kemudian diproses menjadi relief image dan diimplementasikan pada mesin CNC router GWeike WK1212 dengan teknik proses permesinan relief cutting.

Bentuk tahapan solusi tersebut dilakukan dalam 3 tahapan, yaitu Computer Aid Design (CAD), Computer Aid Machining (CAM), dan diakhiri dengan tahapan proses CNC. Tahapan CAD dilakukan dengan menentukan raw image berwarna kemudian dilakukan filtering untuk mereduksi noise gambar dan ditransformasi menjadi mage grayscale menggunakan metode average dan weighting image grayscale. Kemudian dilakukan pengaturan tingkat luminosity agar diperoleh tingkat pencahayaan yang sesuai.

Setelah diperoleh image grayscale dengan tingkat luminosity yang sesuai maka dilanjutkan dengan proses CAM untuk dirubah menjadi relief image atau desain image 3D berdasarkan gradasi warna grayscale. Selanjutnya, diukur nilai depth proses dan dilakukan toolpathing untuk rough cutting dan finish cutting serta disimulasikan terlebih dahulu untuk proses permesinannya. Proses selanjutnya diakhiri dengan permesinan $\mathrm{CNC}$ dengan teknik proses relief cutting sehinggan diperoleh hasil fisik objek 3D relief berdasarkan relief image yang digunakan.

\section{HASIL DAN PEMBAHASAN}

\subsection{Computer Aid Design (CAD)}

Pada tahapan proses CAD menggunakan metode image lithopane processing untuk merubah image 2D menjadi desain visual 3D digunakan teknik luminosity grayscaling. Tahapan tersebut dimulai dari pemilihan objek 
image foto berwarna yang sesuai, dalam artian foto yang digunakan haruslah memiliki karakteristik minim komponen distraksi agar tidak terdapat banyak profil-profil noise ketika diproses CNC nantinya seperti pada Gambar 1.

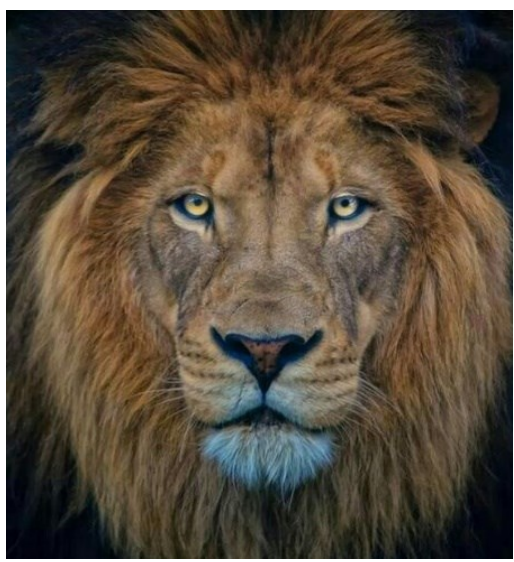

Gambar 1. Raw Image

Proses transformasi menjadi image grayscale menggunakan grayscale mathematical equation modelling. Persamaan matematis untuk membuat image grayscale sendiri terdapat 2 buah pendekatan, yaitu metode rata-rata (average method) dan metode pembobotan (weighted method). Implementasi average method dapat dilihat pada persamaan matematis berikut.

$Y=\left(\frac{R}{3}+\frac{G}{3}+\frac{B}{3}\right)$

Dimana,

$\mathrm{Y}=$ Grayscale

$\mathrm{R}=$ Red Color

$\mathrm{G}=$ Green Color

$\mathrm{B}=$ Blue Color

Apabila menggunakan rentang bobot $100 \%$, maka akan diperoleh nilai grayscale adalah $\mathrm{R}=33,3 \%, \mathrm{G}=33,3 \%$ dan $\mathrm{B}=33,3 \%$. Hasil image grayscale tersebut dapat dilihat pada Gambar 2.

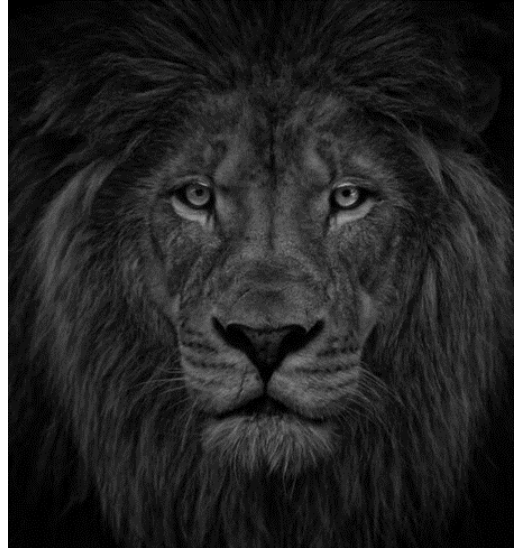

Gambar 2. Image Grayscale Average Method

Selanjutnya, apabila menggunakan weighting method maka nilai koefisien RGB akan disesuaikan. Hal ini dikarenakan pembobotan pada weighting method akan disesuikan dengan tingkat luminosity atau intensitas cahaya, sehingga hasil image grayscale-nya akan terlihat lebih terang. Implementasi weighted method dapat dilihat pada persamaan matematis berikut.

$Y=(0,3 R+0,59 G+0,11 B)$

Menggunakan rentang bobot $100 \%$, maka akan diperoleh nilai grayscale adalah $\mathrm{R}=30 \%, \mathrm{G}=59 \%$ dan $\mathrm{B}=11 \%$. Hasil kalkulasi persamaan tersebut menunjukkan bahwa nilai bobot $\mathrm{G}$ menjadi lebih besar dan nilai bobot $\mathrm{B}$ menjadi lebih kecil, sedangkan nilai bobot $\mathrm{R}$ tidak berubah signifikan. Hasil pembobotan tersebut akan mempengaruhi tingkat intensitas cahaya dari objek image grayscale dan tentu saja terlihat secara visual menjadi sedikit lebih cerah. Hasil image grayscale tersebut dapat dilihat pada Gambar 3.

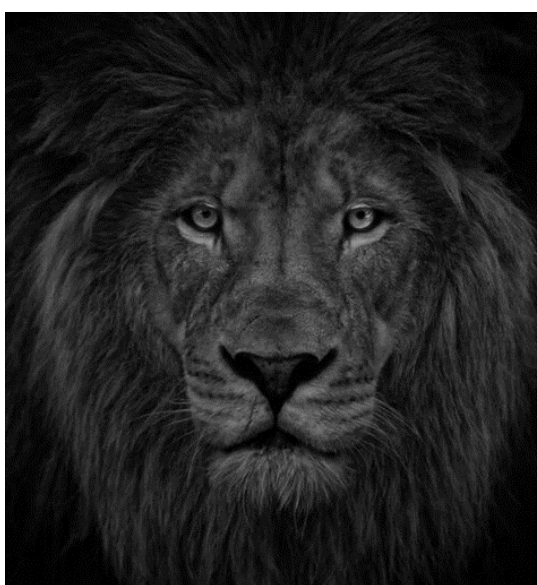

Gambar 3. Image Grayscale Weighted Method 
Proses pembuatan image grayscale sendiri menggunakan bantuan software CAD. Hasil nilai pembobotan dari weighted Method menjadi inputan di dalam software CAD tersebut seperti pada Gambar 4. Secara visual hasil image grayscale dari implementasi weighted method terlihat lebih cerah dibanding dengan average method walaupun tidak begitu signifikan. Pada proses permesinan $\mathrm{CNC}$ terutama untuk teknik proses relief cutting diperlukan nilai luminosity yang sesuai, dalam hal ini hasil image grayscale dari weighted method secara visual masih dirasa tingkat luminosity-nya masih rendah. Hal ini dikarenakan image tersebut secara visual intensitas cahaya masih kurang, sedangkan proses relief cutting membaca image grayscale berdasarkan tingkat gelap-terang yang jelas. Apabila nilai luminosity-nya rendah maka hasil proses relief cutting akan cenderung tidak nampak.

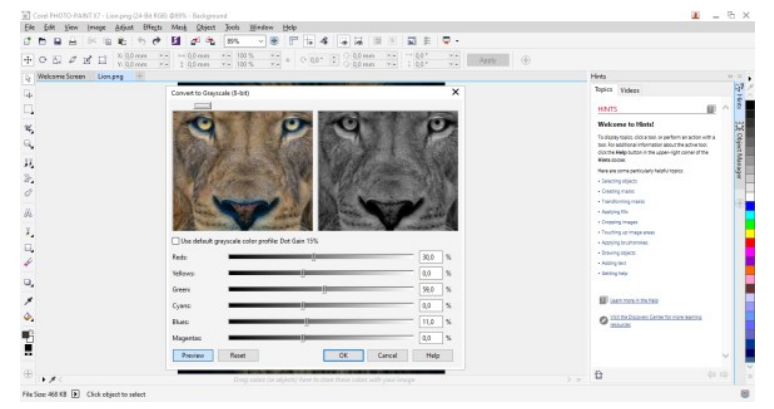

Gambar 4. Proses CAD Image Grayscale

Solusi agar proses permesinan CNC dapat memproses image 2D menjadi objek fisik relief 3D maka pada proses pembuatan image grayscale nilai luminosity perlu diperjelas. Teknik luminosity grayscaling digunakan untuk meningkatkan nilai intensitas cahaya pada image grayscale tersebut dengan cara menggunakan pemodelan matematis sebagai berikut.

$$
L=\frac{1}{2}(\operatorname{Max} R G B+\operatorname{Min} R G B)
$$

Dimana,

$\mathrm{L}=$ Luminosity

Max RGB $=$ Nilai RGB maksimum

Min $\mathrm{RGB}=$ Nilai RGB minimum

Perlu kita ketahui bahwa pada image grayscale tingkat nilai luminosity memiliki rentang dari 0 sampai dengan 255. Artinya bahwa semakin rendah nilai luminosity maka image grayscale akan semakin gelap dan begitu juga sebaliknya, semakin tinggi nilai luminosity maka image grayscale akan semakin terang. Apabila hal ini perlu menjadi pertimbangan karena pada proses permesinan $\mathrm{CNC}$ teknik relief cutting membaca image grayscale berdasarkan nilai luminosity, artinya semakin rendah ataupun tinggi maka hasil proses tidak akan optimal karena pola relief 3D tidak akan terbentuk sempurna. Agar didapatkan nilai luminosity yang sesuai maka perlu dilakukan kalkulasi menggunakan pendekatan model matematis di atas, sebagai berikut.

Pertama perlu diketahui nilai luminosity existing dari implementasi penggunaan kedua metode grayscaling di atas. Pengukuran nilai luminosity dari implementasi average method adalah sebagai berikut.

$\mathrm{R}=33,3 \%=0,33$

$\mathrm{G}=33,3 \%=0,33$

$\mathrm{B}=33,3 \%=0,33$

$L=\frac{1}{2}(0,33+0,33)=0,33=33,3 \%$

Nilai luminosity yang dihasilkan dari average method adalah sebesar 33,3\% dari 255 atau berada pada nilai $84,915 \approx 85$. Selanjutnya, pengukuran nilai luminosity dari implementasi weighted method adalah sebagai berikut.

$$
\begin{aligned}
& \mathrm{R}=30 \%=0,3 \\
& \mathrm{G}=59 \%=0,59 \\
& \mathrm{~B}=11 \%=0,11 \\
& L=\frac{1}{2}(0,59+0,11)=\frac{1}{2}(0,7)=0,35=35 \%
\end{aligned}
$$

Nilai luminosity yang dihasilkan dari weighted method adalah sebesar $35 \%$ dari 255 atau berada pada nilai $89,25 \approx 89$. Hasil nilai luminosity dari kedua metode di atas terlihat berbeda. Namun, apabila dibuktikan pada hasil image grayscale dari kedua metode tersebut terlihat tidak berbeda secara signifikan, hal ini dikarenakan adanya faktor persepsi visual. Perlu diketahui bahwa penilaian hasil grayscale setiap foto apabila dibandingkan dengan menggunakan kedua metode di atas selain tergantung pada faktor nilai luminosity juga bergantung pada faktor persepsi visual masing-masing orang.

Nilai luminosity sebesar 85 dari hasil average method maupun weighted method sebesar 89 terlihat sama-sama masih pada 
rentang nilai luminosity luminosity yang ideal apabila akan dilanjutkan pada proses permesinan CNC dengan teknik relief cutting. Hal ini dikarenakan kedua nilai tersebut masih jauh dibawah nilai luminosity maksimal grayscale sebesar 255. Apabila image grayscale tetap digunakan maka hasil relief cutting tidak akan optimal karena profil relief cenderung tidak tebentuk konturnya karena minimnya nilai luminosity.

Solusi agar dapat diproses pada permesinan CNC secara baik maka perlu adanya peningkatan nilai luminosity, namun perlu menjadi catatan bahwa penelitian ini tidak mengkaji berapa nilai luminosity image grayscale yang optimal agar mesin $\mathrm{CNC}$ dapat melakukan proses relief cutting secara optimal. Pada penelitian ini nilai luminosity dari image grayscale akan ditingkatkan berdasarkan persepsi visual peneliti mengacu pada kondisi yang ideal atau kondisi yang masih dipandang feasible untuk dapat diproses menggunakan $\mathrm{CNC}$ secara baik seperti yang ditunjukkan pada Gambar 5.

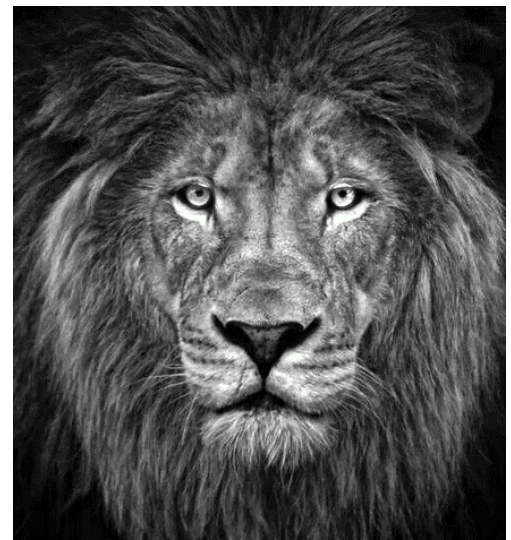

Gambar 5. Peningkatan Luminosity Grayscale

Rentang nilai luminosity secara umum diukur pada skala $\mathrm{L}[0,1]$, bila dikonversi pada rentang tingkat luminosity grayscale adalah $\mathrm{L}$ $[0,255]$. Untuk meningkatkan nilai luminosity grayscale maka perlu menggunakan acuan, pada penelitian ini menggunakan nilai luminosity weighted method sebesar 0,35 pada skala $[0,1]$ atau sebesar $89,25 \approx 89$ pada skala $[0,255]$. Selanjutnya nilai luminosity tersebut ditingkatkan sebesar $50 \%$ menggunakan software CAD dengan tujuan tingkat luminosity akan bertambah, sebagai berikut.
$L=L_{0}+\left(\left(255-L_{0}\right) \frac{\alpha}{100}\right)$

Dimana,

$\mathrm{L}_{0}=\mathrm{L}$ awal

$\alpha=$ persentase peningkatan

Maka, pengukuran peningkatan nilai luminosity grayscale dengan ukuran peningkatan sebesar $50 \%$ dari nilai luminosity awal adalah sebagai berikut.

$$
\begin{aligned}
L & =89+\left((255-89) \frac{50}{100}\right) \\
& =89+83 \\
& =172
\end{aligned}
$$

Hasil peningkatan sebesar 50\% dari nilai luminosity awal 89 menunjukkan nilai sebesar 172 pada skala $L[0,255]$ atau apabila dikonversi pada skala $L[0,1]$ adalah sebesar 0,67 atau $67 \%$. Hasil nilai peningkatan luminosity tersebut terlihat cukup signifikan sehingga berdampak pada peningkatan intensitas cahaya image grayscale seperti yang ditunjukkan pada gambar 4.6 di atas. Setelah proses CAD selesai dengan diperolehnya image grayscale dengan nilai luminosity yang sesuai, selanjutnya dilakukan proses perancangan CAM menggunakan bantuan software UcanCAM.

\subsection{Computer Aid Machining (CAM)}

Pada proses CAM hasil image grayscale akan diproses untuk seting proses permesinan relief cutting pada mesin $\mathrm{CNC}$ router. Proses CAM sendiri akan dilakukan beberapa tahap yaitu dimulai dari pemilihan teknik proses, toolpathing dan generate gcode. Pada teknik proses relief cutting atau yang juga dikenal sebagai image relief machining desain 2D akan diproses menjadi 3D relief pada permesinan CNC dengan terlebih dahulu dilakukan seting toolpath alur proses dan penggunaan mata pahat yang sesuai.

Proses relief cutting pada penelitian ini dilakukan dalam 2 tahapan, yaitu tahap rough cut dan finish cut atau dikenal juga sebagai proses multi step cutting. Proses rough cut merupakan proses pada permesinan CNC untuk membuat potongan kasar terlebih dahulu, sehingga hasil yang diperoleh adalah kontur awal yang masih kasar. Proses rough cut ini memiliki kelebihan dalam membuat kontur dasar secara cepat walaupun hasilnya masih kasar. Proses selanjutnya adalah finish cuti yaitu proses pada permesinan $\mathrm{CNC}$ untuk membuat 
potongan finishing sehingga hasil akhirnya adalah kontur halus sesuai dengan desain.

Proses relief cutting sendiri sebenarnya dapat langsung dilakukan dalam 1 kali tahap proses yaitu dalam hal ini langsung pada finish cut. Namun hal ini tentu saja terdapat beberapa kekurangan, diantaranya adalah untuk desain relief yang memiliki pola profil yang dalam maka potensi mata pahat patah akan besar karena mata pahat yang digunakan pada finish cut adalah jenis conical $3 \mathrm{~mm}$. Sehingga proses kombinasi diperlukan untuk mengurangi resiko tersebut, yaitu dengan kombinasi antara proses rough cut menggunakan mata pahat end mill dan finish cut dengan mata pahat conical. Pada penelitian ini proses rough cut menggunakan mata pahat end mill diameter $3 \mathrm{~mm}$ dengan jumlah flute atau mata pisau adalah 2, untuk proses toolpathing terlihat pada Gambar 6 .

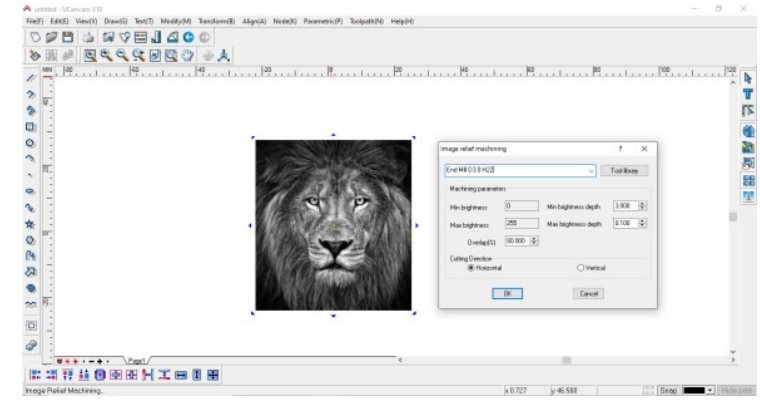

Gambar 6. Rough Cut Toolpathing

Proses relief cutting pada image grayscale dalam penelitian ini menggunakan tingkat kedalaman (depth) sebesar 3mm. Menggunakan mata pahat end mill $3 \mathrm{~mm} 2$ flute pada proses rough cut material kayu mahoni yang digunakan pada penelitian ini akan dikikis sampai dengan menghasilkan potongan kasar. Selanjutnya akan dilanjutkan dengan proses finish cut menggunakan mata pahat conical $3 \mathrm{~mm}$ yang bertujuan untuk proses finishing agar menghasilkan kontur relief sesuai dengan desain yang dikehendaki. Seting toolpathing untuk proses finish cut seperti yang ditunjukkan pada Gambar 7.

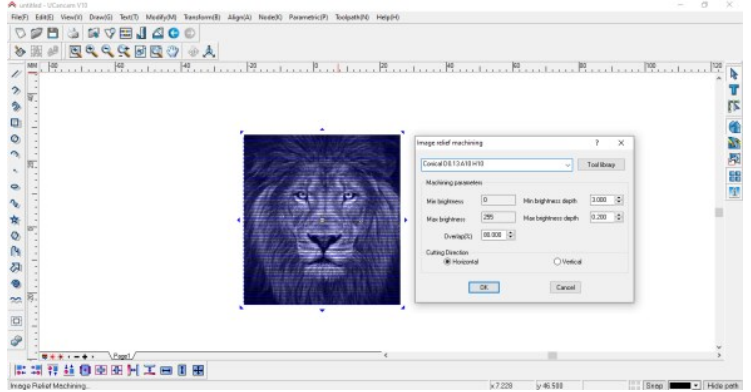

Gambar 7. Finish Cut Toolpathing

Menggunakan nilai luminosity dari image grayscale sebesar 172 pada desain objek sebelumnya, dapat diketahui tingkat depth dari prosesnya. Nilai total depth yang didapatkan dari hasil proses $\mathrm{CNC}$ dapat diketahui dengan model matematis berikut.

$Z=\left(Z_{\min } *\left(\frac{L}{255}\right)\right)-Z_{\max }$

Dimana,

$\mathrm{Z}=$ total depth perolehan

$\mathrm{Z}_{\text {min }}=$ depth minimum berdasarkan tingkat luminosity (diukur dari permukaan material)

$\mathrm{Z}_{\max }=$ depth minimum berdasarkan tingkat luminosity (diukur dari permukaan material)

$\mathrm{L}=$ luminosity image grayscale

Maka untuk mengetahui nilai total depth perolehan dari proses relief cut adalah sebagai berikut.

$$
\begin{aligned}
Z & =\left(3 *\left(\frac{172}{255}\right)\right)-0,2 \\
& =2,02-0,1=1,82 \mathrm{~mm}
\end{aligned}
$$

Hasil perolehan nilai depth sebesar 1,82 $\mathrm{mm}$ adalah berdasarkan nilai luminosity dari image grayscale sebelumnya yaitu 172 . Apabila nilai depth minimal diseting sebesar $3 \mathrm{~mm}$, maka nilai tersebut hanya dapat tercapai apabila nilai luminosity-nya berada pada tingkat maksimum atau sebesar 255. Sedangkan dengan nilai luminosity 172 maka tentu saja nilai perolehan depth akan menyesuaikan. Simulasi dari proses rough cut dan finish cut dapat dilihat pada Gambar 8. 


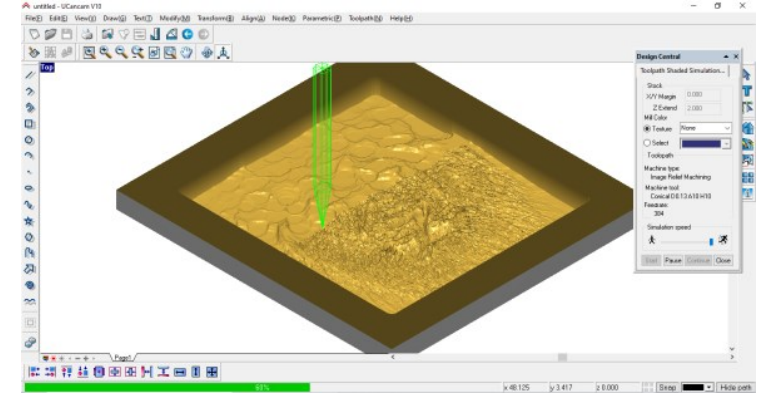

Gambar 8. Simulasi Proses Relief Cutting

Simulasi dari proses relief cutting di atas selanjutnya akan diperoleh visualisasi hasil relief objek secara simulasi. Adapun hasil relief dapat dilihat pada Gambar 9.

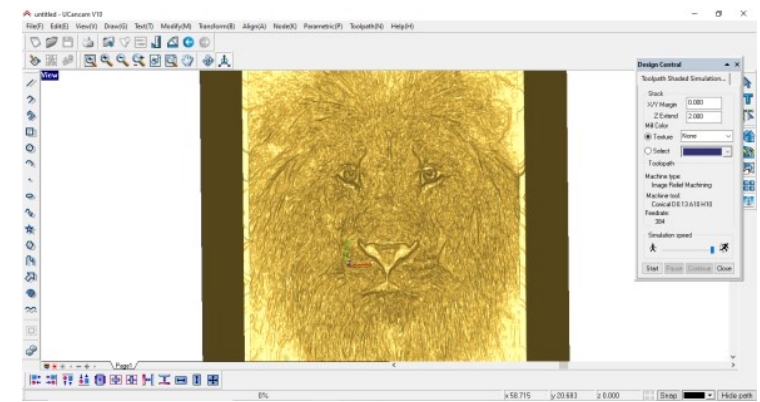

Gambar 9. Visualisasi Hasil Relief Cutting

\subsection{CNC Router Processing}

Proses berikutnya dari penelitian ini adalah implementasi dari perancangan CAM untuk image grayscale yang telah dibuat kedalam operasi permesinan CNC router. Mesin $\mathrm{CNC}$ router yang digunakan pada penelitian ini adalah G-Weike WK1212. Pada proses CAM sebelumnya, image grayscale telah dirancang untuk dilakukan 2 tahapan proses relief cutting yaitu tahapan proses rough cut dan finish cut. Implementasi proses rough cut menggunakan mata pahat end mill $3 \mathrm{~mm} 2$ flute dapat dilihat pada Gambar 10.

Proses rough cut di atas menggunakan acuan level seting mesin pada penelitian sebelumnya, yaitu motion speed sebesar 7 step dan spindle speed sebesar 6 step pada DSP controller mesin CNC. Proses rough cut sendiri bertujuan untuk menghasilkan kontur potongan kasar dari objek relief. Tujuannya adalah mengurangi beban kerja dari mata pahat conical yang digunakan pada proses finish cut agar tidak terjadi cracking atau patah. Hal ini dikarenakan mata pahat conical dengan diameter $3 \mathrm{~mm}$ memiliki karakteristik yang sangat mudah patah apabila digunakan untuk proses dengan depth yang dalam. Implementasi dari proses finish cut dapat dilihat pada Gambar 11.

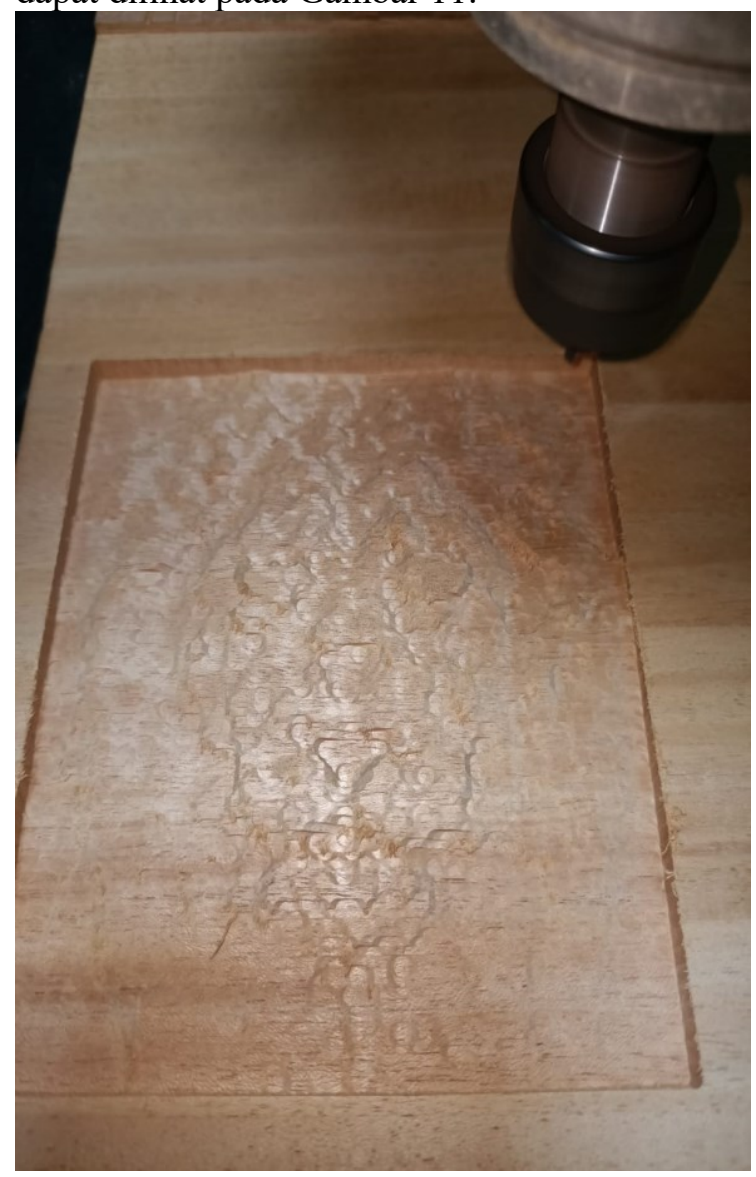

Gambar 10. Proses CNC Rough Cutting

Hasil finish cut di atas memperlihatkan luaran hasil objek relief dari proses permesinan $\mathrm{CNC}$ router yang menyerupai desain image grayscale awal. Setiap profil terbentuk sempurna dengan kontur-kontur relief yang terbentuk berdasarkan tingkat luminosity dari image grayscale yang digunakan. Proses finish cut tersebut dilakukan dengan menggunakan mata pahat conical $3 \mathrm{~mm}$ dengan level seting pada DSP controller mesin CNC router adalah motion speed sebesar 10 step dan spindle speed sebesar 8 step. Nilai level seting tersebut berbeda debandingkan dengan pada proses rough cut, hal ini bertujuan agar proses finish cut dapat dilakukan dengan cepat oleh karena beban material yang dipotong telah berkurang dengan adanya proses rough cut sebelumnya sehingga mata pahat conical pada proses finish cut ini dapat dimaksimalkan kinerjanya tanpa khawatir terjadi patah. 


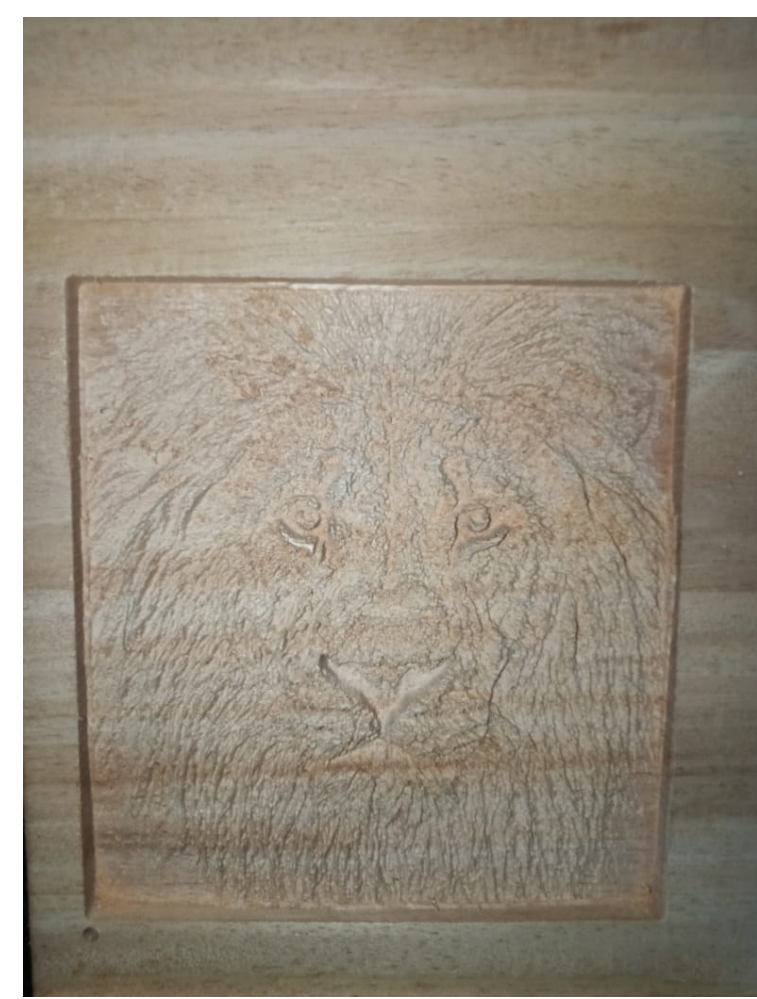

Gambar 11. Proses CNC Finish Cutting

\section{KESIMPULAN}

Memanfaatkan metode image litophane processing untuk merubah image $2 \mathrm{D}$ menjadi image desain 3D dapat dilakukan dengan teknik luminosity grayscalling, dimana menggunakan pendekatan weighted method diperoleh nilai komposisi warna untuk merubah image warna menjadi grayscale sebesar 33\% red, 59\% green dan $11 \%$ blue dengan nilai luminosity sebesar $35 \%$ atau 89 dari rentang tingkat luminosity grayscale 0 - 255 .

Pada permesinan $\mathrm{CNC}$ router G-Weike WK1212 untuk merealisasikan desain image grayscale menjadi 3D objek maka proses yang digunakan adalah relief cutting, dimana pada proses tersebut nilai luminosity dari image grayscale awal yaitu 89 akan ditingkatkan sebesar 50\% menjadi 172 atau $67 \%$ dari rentang tingkat luminosity grayscale $\mathrm{L}[0,255]$ sehingga akan berada pada nilai luminosity yang ideal untuk proses relief cutting mengingat pada proses cutting tersebut akan berdasarkan kecerahan luminosity dari suatu image. Nilai luminosity yang terlalu rendah akan menyebabkan proses relief cutting tidak akan optimal karena depth relief hasil pengerjaan akan menjadi sangat rendah atau dalam arti pola relief tidak akan kelihatan karena mendekati dasar material. Sebaliknya apabila nilai luminosity terlalu tinggi maka pola relief juga tidak akan terlihat karena hanya menggores tipis di permukaan atas material. Menggunakan nilai luminosity sebesar 172 dari image grayscale maka diperoleh nilai depth aktual sebesar $1,82 \mathrm{~mm}$ dari total depth $3 \mathrm{~mm}$, yang tentu saja pola relief akan terlihat secara baik.

\section{DAFTAR PUSTAKA}

Dewa, K. W, Herwin, S., \& Dony, S. N. (2020). Optimasi Proses Cutting Mesin CNC Router G-Weike WK1212 dengan Metode Full Factorial Design dan Optimasi Plot Multi Respon. Jurnal Penelitian dan Aplikasi Sistem \& Teknik Industri (PASTI), XIV(1), $1-14$. https://doi.org/10.22441/pasti.2020.v14i1. 001

Herwin, S., \& Dewa, K. W. (2020). Optimasi Permesinan CNC Router untuk Proses Cutting Material Kayu Mahoni Menggunakan Mata Pahat End Mill 3mm Tungsten Carbide. Jurnal Teknik Industri, 10(3), 227-239. https://doi.org/10.25105/jti.v10i3.8408

Darmawanto, E., \& Minardi, J. (2017). Pengembangan Produk Ukir Berbasis Desain 3 Dimensi Menggunakan Mesin Cnc Untuk Industri Mebel. Disprotek, $8(1), 67-80$.

Ginting, R., Hadiyoso, S., \& Aulia, S. (2017). Implementation 3-Axis CNC Router for Small Scale Industry. International Journal of Applied Engineering Research, 12(17), 6553-6558. http://www.ripublication.com

Lungu, A., Ispas, M., Brenci, L. M., Răcăşan, S., \& Coşereanu, C. (2021). Comparative study on wood cnc routing methods for transposing a traditional motif from romanian textile heritage into furniture decoration. Applied Sciences (Switzerland), 11(15). https://doi.org/10.3390/app11156713

PW, A., \& I, S. (2016). Aplication of Technology 4-Axis CNC Milling for Manufacturing Artistic Ring. Advances in Automobile Engineering, 01(S1), 1-6. https://doi.org/10.4172/2167-7670.s1-007

Setyaningsih, N. Y. D., Annudin, K., \& Solekhan, S. (2021). The Influence of 
Ruggedness Reviews 3-Dimensional Photo Carving Media Based on 3-Axis CNC Router. Journal of Robotics and Control (JRC), 2(3), 212-216. https://doi.org/10.18196/jrc.2381

Sood, S., Duvedi, R. K., Bedi, S., \& Mann, S. (2018). 3D representation and CNC machining of 2D digital images. Procedia Manufacturing, 26, 10-20. https://doi.org/10.1016/j.promfg.2018.07. 001

Wu, Y., You, H., Zhao, D., \& Liu, Y. (2012). $\mathrm{CNC}$ machining and simulation for relief of special-shaped stone. Advanced Materials Research, 468-471, 69-73. https://doi.org/10.4028/www.scientific.net /AMR.468-471.69
Yang, N. E., Lee, J. W., \& Park, R. H. (2013). Depth Map Generation Using Local Depth Hypothesis for 2D-TO-3D Conversion. International Journal of Computer Graphics \& Animation, 3(1), 1-15. https://doi.org/10.5121/ijcga.2013.3101

Yu, Y. (2017). Design and Simulation of CAD / CAM Embossing Process for Aluminum Alloy Thin- Wall Parts. 156(Meici), 671676. https://doi.org/10.2991/meici- 